\title{
Walking behaviour of healthy elderly: attention should be paid
}

\author{
Eling D de Bruin", André Schmidt
}

\begin{abstract}
Background: Previous studies have reported an association between executive function (EF) and measures of gait, particularly among older adults. This study examined the relationship between specific components of executive functions and the relative dual task costs of gait (DTC) in community-dwelling non-demented older adults, aged 65 years and older.
\end{abstract}

Methods: Temporal (stride time, stride velocity) and spatial (stride length) gait characteristics were measured using a GAITRite ${ }^{\oplus}$-System among 62 healthy community dwelling older adults while walking with and without backward counting (BC) at preferred and fast walking speeds. Specific executive functions divided attention, memory and inhibition were assessed using the Test for Attentional Performance (TAP). Other measures included Mini-Mental State Examination (MMSE), amount of daily medications taken, educational level and sociodemographic characteristics. Adjusted and unadjusted multivariable linear regression models were developed to assess the relations between variables.

Results: High relative DTC for stride time, stride velocity and stride length were associated with divided attention at fast walking speed. High relative DTC for stride time was associated with divided attention at preferred walking speed. The association between high DTC of stride length and memory was less robust and only observable at preferred walking speed. None of the gait measures was associated with inhibition.

Conclusions: Spatial and temporal dual task cost characteristics of gait are especially associated with divided attention in older adults. The results showed that the associated DTC differ by executive function and the nature of the task (preferred versus fast walking). Further research is warranted to determine whether improvement in divided attention translates to better performance on selected complex walking tasks.

\section{Background}

In the growing population of older people falling is a common problem. Approximately $30 \%$ of older adults experience a fall each year [1-3], and fall incidence is even higher (50\%) in women aged 85 and above [4]. Gait problems and weakness are a common specific precipitating cause for falls [5], and persons with a walking disability have an increased risk of repeated falls [6] and a reduced survival compared to peers with normal walking $[7,8]$. In light of these negative consequences, much research has been directed towards the determinants of walking disability. There are indications that the influence of motor and sensory impairments on falls is in part moderated by executive functioning [9].

\footnotetext{
* Correspondence: debruin@move.biol.ethz.ch

Institute of Human Movement Sciences and Sport, ETH Zurich, HIT J 32.3; Wolfgang-Pauli-Strasse 37, CH-8093 Zürich, Switzerland
}

Various studies have shown that, in contrast to past believes, gait performance is not only an automated sequence of body movements. Cognitive functions also play an important role in the control of gait. These cognitive functions are mostly attributed to so-called executive control processes of the human brain [10-12]. A recent review on this topic summarizes the interplay between executive functions, attention and gait [13]. Executive function (EF) refers to cognitive processes that control and integrate other cognitive activities $[14,15]$, and this term has been used to describe a group of cognitive actions that include: dealing with novelty, planning and implementing strategies for performance, monitoring performance, using feedback to adjust future responding, vigilance, and inhibiting task-irrelevant information [14] of lower level, more modular, or automatic functions [16]. Common tasks of daily life require 
attention, rapid motor planning process, and effective inhibition of irrelevant or inappropriate details. Older adults, however, experience increasing difficulties in maintaining multiple task rules in working memory [17].

Existing knowledge about the interplay between EF and gait is mostly derived from studies that measured and reported EF as a composite score $[12,18,19]$. Relatively few studies have focused on the age-related deficits in specific components of executive function and most of these studies were based on a traditional set of tests of executive function, without detailing specific components. The conclusions drawn from these studies might, therefore, be limited by their methodologies. The putative executive measures might not load on a single executive construct, and might overlap with each other $[20,21]$. The differential breakdown for the executive functioning performance across patients with chronic schizophrenia, for example, suggests that the fractionation of central executive functioning occurs in schizophrenia and not all EF components are in each case equally impaired in their performance [22]. Preliminary evidence suggests that also in normal aging there are selective deficits in executive function rather than a general decline [23-26]. These studies, thus, suggest that the fractionation of executive function is necessary when the EF effects on gait are studied.

Three components of EF $\left(\mathrm{EF}_{\mathrm{comp}}\right)$ are mentioned in the literature as being related to gait: "working memory" [27], "divided attention" [11], and "inhibition" [28]. It is unclear whether these components relate to gait with comparable portions. Furthermore, it is unclear whether these measures are independent in explaining variability in gait. The aim of this study was to determine whether dual-task costs of gait in healthy elderly are explained by these three $\mathrm{EF}_{\text {comp. We hypothesised that divided }}$ attention, memory and inhibition each explain comparable portions of dual-task costs of gait measures in elderly community dwellers.

\section{Methods}

The sample for this cross-sectional analysis consisted of sixty-nine healthy elderly subjects who consented to perform the measurements. Subjects were free of any orthopaedic disorder of the lower limb that might affect their gait, and did not report acute pain or any other complaint likely to influence walking. Subjects were recruited from the local community using various strategies. Senior subjects attending exercise classes of the Academic Sports Club Zurich (ASVZ "Akademischer Sportverein Zürich") were approached shortly before their training started. The study was also presented at a "senior university" lecture at the University of Zurich, Zurich, Switzerland. After a short presentation leaflets about the study were distributed in which interested individuals were encouraged to contact us. Furthermore, sport events for seniors were visited to recruit volunteers. In addition an advertisement in the ETH magazine "ETH Life Print" with information on the study was published (edition May, 2008). The institutional review board of the ETH Zurich provided approval for the project and all subjects provided written informed consent.

Inclusion criteria were age 65 or above and the ability to walk without walking aids. Exclusion criteria were a score below 25 on the Mini Mental Status Examination (MMSE) [29], medically diagnosed gait impairments of neurologic and/or orthopaedic origin, and any musculoskeletal impairments that influence gait pattern.

\section{Gait analysis}

In order to assess temporal-spatial characteristics of gait we used the GAITRite system (CIR Systems Inc., Havertown (PA), USA). The system was $13 \mathrm{~m}$ long and $0.89 \mathrm{~m}$ wide, with an active sensor area of $7.32 \mathrm{~m}$ long and $0.61 \mathrm{~m}$ wide. The sampling rate of the system is 80 Hz. Spatial-temporal gait parameters were processed and stored using the application software. Studies have reported both high reliability and validity of the GAITRite ${ }^{\circ}$ system for measuring spatial and temporal gait characteristics in older subjects [30-34].

\section{Procedure}

Testing was performed in the gait laboratory of the City Hospital Waid in Zurich, Switzerland. To measure steady state walking, the central $7.32 \mathrm{~m}$ active sensor area of the GAITRite ${ }^{\circ}$ system was used as the test distance. During the measurements, the subjects walked on the walkway while wearing their own comfortable clothing and low-heeled habitual shoes. Since mean values of eight strides have been shown to be appropriately representing gait characteristics and can be considered as representative of normal gait [33] we ensured the capturing of at least 25 steps per test condition. Each subject was instructed to walk the walkway three times, in randomised order, at I) self-selected comfortable speed, II) a self-selected higher speed, III) a self-selected comfortable speed with a working memory task, and IV) a self-selected higher speed with a working memory task, making a total of 12 walks per individual. Participants were not specifically instructed to prioritize either one of both tasks, but were asked to combine both tasks at their best capacity.

In the working memory task the subjects walked while reciting out loud serial subtractions of seven, starting from a given random number between 200 and 250 . Before performing the task while walking, the participants were allowed to practice while sitting, in order to evaluate basic problems in calculating. The sequence of 
numbers was reported on protocols. Evaluation of performance on the serial 7 subtraction included the total number of subtractions and the number of mistakes made during calculation. Only successful trials were used for further data analysis.

Since the relation between measures of gait and executive function were demonstrated for complex conditions $[35,36]$, and we wanted to account for individual differences [13] we examined the relation for the interference between task conditions I vs. III, and II vs. IV. This was expressed as relative dual task costs (DTC) of walking with the formula DTC $[\%]=100 *$ (single-task score dual-task score)/single-task score [37]. Stride length $(\mathrm{cm})$, stride velocity $(\mathrm{cm} / \mathrm{s})$ and stride time $(\mathrm{s})$ of the left foot were evaluated. Values were expressed as Mean \pm SD.

\section{Cognitive assessment}

All subjects underwent neuropsychological assessment with the Test for Attentional Performance ("Testbatterie zur Aufmerksamkeitsprüfung" (TAP)) [38], which took less than 20 minutes, across the cognitive domains attention, memory and executive functions. The core of the procedures is reaction time tasks of low complexity allowing the evaluation of very specific deficiencies. The tasks consist of simple and easily distinguishable stimuli that the participants react to by a simple motor response. The procedures included in the test battery were: Divided Attention, Go/No-Go, and Working Memory. The TAP test has previously been shown to be both reliable and valid $[39,40]$ and offers values for normative and brain injured populations [41,42].

- The divided attention performance assessment is realized by a visual and an acoustical task. The visual task consists of crosses that appear in a random configuration in a $4 \times 4$ matrix. The subject has to detect whether the crosses form the corners of a square. The acoustical task includes a regular sequence of high and low beeps. The subject has to detect an irregularity in the sequence.

- In the go/no-go tasks, the subject has to react selectively to one class of stimuli but not to others. For testing a go/no-go-task was realized with a high memory load with five stimuli, squares with different textures, where two were targets. The aim of this examination is an assessment of the capacity of focused attention (reject irrelevant information).

- The working memory task requires a continuous control of the information flow through short-term memory. For this, numbers are presented on the screen that must be compared with previously exposed numbers. The repetition of a number within a short interval has to be answered by pressing a key.
For these three tests of $\mathrm{EF}_{\text {comp }}$, we analysed the number of omissions for the subtests "divided attention" and "working memory". In the subtest "Go/No-Go" the number of errors was taken. Each of these tests took 5 minutes. The subject had the opportunity to practice by means of a few examples and was allowed to ask the instructor for help. During the main test the subjects had to act on their own.

\section{Sociodemographic characteristics and other measures}

Sociodemographic variables and descriptive variables were obtained through the use of a standardized questionnaire and by a semi-structured interview. These variables included age, gender, body height and weight, years of completed education, living status, self-reported chronic conditions, use of medication, falls in the previous half year, and concern about falling [43] (Table 1).

\section{Data analysis}

Descriptive statistics were used to evaluate participants' demographic characteristics (Table 1). Changes in DTC

Table 1 Baseline and gait characteristics of subjects

\begin{tabular}{lc}
\hline & Subjects \\
\hline Age, years (mean $\pm \mathrm{SD})$ & $72.5 \pm 5.9$ \\
\hline Weight $(\mathrm{kg})$ & $70.2 \pm 10.7$ \\
\hline Height $(\mathrm{cm})$ & $170 \pm 7.9$ \\
\hline Females $(\mathrm{N}, \%)$ & $28,44 \%$ \\
\hline MMSE (points) & $28.1 \pm 1.3$ \\
\hline FES-I (points) & $17.3 \pm 1.5$ \\
\hline Education (years) & $14.6 \pm 2.6$ \\
\hline Living status & 31 \\
$\quad$ One person household (\%) & 69 \\
\hline
\end{tabular}

Number of self-reported chronic diseases (\%)

$\begin{array}{ll}\text { Joint pain } & 27.4 \\ \text { Hypertension } & 29.0 \\ \text { none } & 35.5\end{array}$

\begin{tabular}{ll}
\hline Use of hearing aids (\%) & 19.4 \\
\hline Use of visual aids (\%) & 37.1
\end{tabular}

Stride velocity (CS; mean \pm SD; single task/ $1.32 \pm 0.17 / 1.13 \pm 0.3$
dual task; $\mathrm{m} / \mathrm{s}$ )

Stride time (CS; mean \pm SD; single task/dual $\quad 1.1 \pm 0.1 / 1.3 \pm 0.7$ task; seconds)

Stride length (CS; mean \pm SD; single task/dual $1.43 \pm 0.15 / 1.35 \pm 0.18$ task; $\mathrm{m}$ )

Stride velocity (HS; mean \pm SD; single task/ $\quad 1.74 \pm 0.2 / 1.28 \pm 0.34$ dual task; $\mathrm{m} / \mathrm{s}$ )

Stride time (HS; mean \pm SD; single task/dual $\quad 0.9 \pm 0.1 / 1.2 \pm 0.7$ task; seconds)

Stride length (HS; mean \pm SD; single task/dual $1.62 \pm 0.16 / 1.41 \pm 0.19$ task; $m$ )

MMSE: mini mental state examination; FES-I: falls efficacy scale-international; CS: self-selected comfortable speed; HS: self-selected higher speed. 
between test conditions (preferred and fast walking) were compared with the paired $t$-test.

A series of simultaneous linear regression models, both unadjusted and adjusted for age, cognition (MMSE), medication use, and years of education, were constructed to examine the association of the main outcome (relative DTC of walking) with the $\mathrm{EF}_{\text {comp. The contribution of }}$ each variable to the regression equation was described in terms of the beta coefficient and the corresponding statistical significance. The adjusted multivariate coefficient of determination $\left(R^{2}\right)$ was used to describe the variability in relative DTC of walking explained by all of the variables of interest entered into the model.

To ensure that the reliability of the regression was not compromised by multicollinearity, we determined the tolerance of each variable before entry into the equation. The experiment-wise Type I error rate was set at 0.05 for the statistical tests. All statistics were performed with SPSS 17.0.

\section{Results}

\section{Subjects}

Seven participants had to be excluded from the analysis. Four individuals were not able to combine the walking test with the serial subtraction task. These individuals were only able to perform both tasks independently. Even after adjusting the task to counting backwards in ones these individuals were not able to combine the tasks. One individual had a MMSE score of 23 and two individuals withdrew because they were ill at the scheduled measurement day. The resulting group consisted of 34 men and 28 women, with a mean age of $72.5 \pm 5.9$ years (range: 65 85 years). Demographic and gait measurement related characteristics of the subjects are presented in table 1.

\section{Linear regression analysis}

A high tolerance and a variance inflation factor (VIF) indicated that the reliability of the estimate of the regression coefficient was not significantly affected by collinearity between the independent variables in the respective equations.

Table 2 reports the results of the adjusted analysis for the DTC of stride velocity. The $R^{2}=.05$ for preferred walking speed Step 1 , the change $(\Delta) R^{2}=.11$ for preferred walking speed Step $2(p=.086)$. The $R^{2}=.38$ for fast walking speed Step 1 , and $\Delta R^{2}=.27$ for fast walking speed Step $2(p<.001)$.

The adjusted analysis for the DTC of stride time and stride length are presented in Tables 3 and $4 . R^{2}=.04$ for preferred walking speed Step $1, \Delta R^{2}=.20$ for preferred walking speed Step $2(p<.01) ; R^{2}=.22$ for fast walking speed Step $1, \Delta R^{2}=.28$ for fast walking speed Step $2(p<.001) . R^{2}=.04$ for preferred walking speed Step $1, \Delta R^{2}=.14$ for preferred walking speed Step 2
Table 2 Regression model for Stride Velocity

\begin{tabular}{lccc}
\hline & $\boldsymbol{B}$ & $\boldsymbol{S E} \boldsymbol{B}$ & $\boldsymbol{\beta}$ \\
\hline Preferred walking speed & & & \\
Step 1 & & & \\
$\quad$ Constant & -81.72 & 75.02 & \\
$\quad$ Age & 0.57 & 0.49 & .16 \\
MMSE & 1.54 & 2.3 & .09 \\
Medications & 0.94 & 1.88 & .07 \\
$\quad$ Years of education & 0.71 & 1.07 & .09 \\
\hline Step 2 & & & \\
$\quad$ Constant & -74.99 & 75.02 & .16 \\
Age & 0.10 & 0.54 & .003 \\
MMSE & 2.01 & 2.30 & .12 \\
Medications & 1.49 & 1.91 & .11 \\
$\quad$ Years of education & 1.43 & 1.10 & .18 \\
Divided attention & 1.24 & 0.98 & .17 \\
Memory & 1.45 & 0.80 & .28 \\
Inhibition & 0.20 & 0.50 & .05 \\
\hline
\end{tabular}

Fast walking speed

\begin{tabular}{lccc} 
Step 1 & & & \\
Constant & 111.36 & 60.73 & \\
Age & 0.43 & 0.40 & .14 \\
MMSE & -4.53 & 1.86 & $-.32^{*}$ \\
Medications & 0.37 & 1.52 & .03 \\
$\quad$ Years of education & 0.70 & 0.86 & .10 \\
\hline Step 2 & & & \\
Constant & 129.87 & 54.28 & \\
Age & -0.004 & 0.39 & -.001 \\
MMSE & -4.59 & 1.64 & $-.33^{* *}$ \\
Medications & 0.31 & 1.36 & .03 \\
Years of education & 1.08 & 0.78 & .16 \\
Divided attention & 3.38 & 0.70 & $.54^{* * *}$ \\
Memory & 0.004 & 0.57 & .001 \\
Inhibition & -0.18 & 0.36 & -.06 \\
\hline
\end{tabular}

MMSE: mini mental state examination.

Note: $R^{2}=.05$ for preferred walking speed Step $1, \Delta R^{2}=.11$ for preferred walking speed Step $2(p=.086) ; R^{2}=.38$ for fast walking speed Step $1, \Delta R^{2}=$ .27 for fast walking speed Step $2(p<.001)$.

${ }^{*}<.05 ;{ }^{* *}<.01 ;{ }^{* * *}<.001$.

$(p<.05) ; R^{2}=.21$ for fast walking speed Step $1, \Delta R^{2}=$ .12 for fast walking speed Step $2(p<.05)$.

Results for the unadjusted analysis (Table 5) show $R^{2}=$ .10 for DTC stride velocity at preferred walking speed $(p=.097), R^{2}=.18$ for DTC stride time at preferred walking speed ( $p<.01), R^{2}=.11$ for DTC stride length at preferred walking speed $(p=.079) ; R^{2}=.31$ for DTC stride velocity at fast walking speed $(p<.001), R^{2}=.28$ for DTC stride time at fast walking speed $(p<.001)$, and $R^{2}=.17$ for DTC stride length at fast walking speed $(p<.05)$. 
Table 3 Regression model for Stride time

\begin{tabular}{lccc}
\hline & $\boldsymbol{B}$ & $\boldsymbol{S E} \boldsymbol{B}$ & $\boldsymbol{\beta}$ \\
\hline Preferred walking speed & & & \\
Step 1 & & & \\
$\quad$ Constant & -78.05 & 181.04 & \\
$\quad$ Age & 0.51 & 1.18 & .06 \\
MMSE & 0.42 & 5.56 & .01 \\
$\quad$ Medications & -0.88 & 4.53 & -.03 \\
Years of education & 3.44 & 2.58 & .18 \\
\hline Step 2 & & & \\
Constant & -43.34 & 173.55 & \\
Age & -0.67 & 1.24 & -.08 \\
MMSE & 0.73 & 5.24 & .02 \\
Medications & -0.91 & 4.36 & -.03 \\
Years of education & 4.55 & 2.50 & .24 \\
$\quad$ Divided attention & 8.01 & 2.24 & $.46^{* * *}$ \\
Memory & 0.64 & 1.83 & .05 \\
Inhibition & -0.09 & 1.14 & -.01 \\
\hline
\end{tabular}

\section{Fast walking speed}

Step 1

$\begin{array}{lccc}\text { Constant } & 198.88 & 260.24 & \\ \text { Age } & 0.49 & 1.70 & .04 \\ \text { MMSE } & -9.79 & 7.99 & -.17 \\ \text { Medications } & -1.64 & 6.52 & -.04 \\ \text { Years of education } & 5.08 & 3.70 & .18\end{array}$

Step 2

$\begin{array}{lccc}\text { Constant } & 271.80 & 235.19 & \\ \text { Age } & -0.84 & 1.68 & -.07 \\ \text { MMSE } & -10.53 & 7.11 & -.18 \\ \text { Medications } & -2.71 & 5.90 & -.06 \\ \text { Years of education } & 5.94 & 3.39 & .22 \\ \text { Divided attention } & 14.44 & 3.04 & .57^{* * *} \\ \text { Memory } & -1.82 & 2.48 & -.10 \\ \text { Inhibition } & -0.95 & 1.55 & -.07\end{array}$

MMSE: mini mental state examination.

Note: $R^{2}=.04$ for preferred walking speed Step $1, \Delta R^{2}=.20$ for preferred walking speed Step $2(p<.01) ; R^{2}=.22$ for fast walking speed Step $1, \Delta R^{2}=$ .28 for fast walking speed Step $2(p<.001)$

${ }^{*}<.05 ; * * 0.01 ; * *<.001$

The mean relative DTC at preferred walking speed was $14.7 \pm 20.7 \%$ (stride velocity), $19.7 \pm 49.5 \%$ (stride time), and $5.9 \pm 9 \%$ (stride length). The mean relative DTC at fast walking speed was $26.4 \pm 17.6 \%$ (stride velocity), $31.4 \pm 71.6 \%$ (stride time), and $12.8 \pm 8.8 \%$ (stride length). The change in DTC caused by the difference in walking speed during testing was significant for all dependent variables: stride velocity, $p<.001$; stride time, $p<.01$; stride length, $p<.001$.

The regression analysis showed that the relative DTC at preferred walking speed was explained by divided
Table 4 Regression model for Stride length

\begin{tabular}{lccc}
\hline & $\boldsymbol{B}$ & $\boldsymbol{S E} \boldsymbol{B}$ & $\boldsymbol{\beta}$ \\
\hline Preferred walking speed & & & \\
& & & \\
Step 1 & & & \\
$\quad$ Constant & -26.44 & 32.99 & \\
$\quad$ Age & 0.12 & 0.22 & .08 \\
MMSE & 0.67 & 1.01 & .09 \\
Medications & 0.79 & 0.83 & .14 \\
Years of education & 0.23 & 0.47 & .07 \\
\hline Step 2 & & & \\
Constant & -23.51 & 32.82 & \\
Age & -0.08 & 0.23 & -.06 \\
MMSE & 0.84 & 0.99 & .12 \\
Medications & 1.30 & 0.82 & .22 \\
Years of education & 0.58 & 0.47 & .17 \\
Divided attention & -0.67 & 0.42 & -.21 \\
Memory & 0.98 & 0.35 & $.43^{* *}$ \\
Inhibition & 0.05 & 0.22 & .03 \\
\hline
\end{tabular}

Fast walking speed

Step 1

\begin{tabular}{lccc} 
Constant & 60.05 & 29.23 & \\
Age & 0.20 & 0.19 & .13 \\
MMSE & -2.47 & 0.90 & $-.35^{* *}$ \\
Medications & 0.78 & 0.73 & .14 \\
Years of education & 0.47 & 0.42 & .14 \\
p 2 & & & \\
Constant & 65.41 & 29.15 & \\
Age & 0.01 & 0.21 & .01 \\
MMSE & -2.42 & 0.88 & $-.34^{* *}$ \\
Medications & 0.84 & 0.73 & .15 \\
Years of education & 0.66 & 0.42 & .20 \\
Divided attention & 1.02 & 0.38 & $.33^{* *}$ \\
Memory & 0.20 & 0.31 & .09 \\
Inhibition & -0.01 & 0.19 & -.01 \\
\hline
\end{tabular}

MMSE: mini mental state examination.

Note: $R^{2}=.04$ for preferred walking speed Step $1, \Delta R^{2}=.14$ for preferred walking speed Step $2(p<.05) ; R^{2}=.21$ for fast walking speed Step $1, \Delta R^{2}=$ .12 for fast walking speed Step $2(p<.05)$.

${ }^{*}<.05 ; *{ }^{*}<.01 ; * * * 0.001$.

attention (stride time, tables $3 \& 5$ ), and working memory (stride length, tables $4 \& 5$ ).

The regression analysis showed that the relative DTC at fast walking speed was explained by the MMSE \& divided attention (stride velocity, tables $2 \& 5$ ), divided attention (stride time, tables 3 \&5), and MMSE \& divided attention (stride length, tables $4 \& 5$ ).

\section{Discussion}

The aim of this study was to determine to which degree the relative dual task costs of walking in healthy elderly are explained by three $\mathrm{EF}_{\text {comp. }}$. We hypothesised that 
distinct brain networks in older adults and reported that no gait measures were associated with, amongst others, regions of the memory domains [48]. Our results seem to be, therefore, somewhat at variance with these results since we found some association between the $\mathrm{EF}_{\text {comp }}$ memory and stride length at preferred walking speed. However, it might well be that the use of another type of neuropsychological assessment would have resulted in differing findings since different types of assessment that pretend to measure the same cognitive construct do not relate to each other and are rather complementary to each other [49].

A large proportion of the variance in DTC of gait is left unexplained in our study. We are aware that many other factors may contribute to the variance in relative DTC of gait, such as genetic and environmental factors [50], interactions between sensory/sensorimotor and cognitive functions [51], or visual observation skills [52]. The fact that we did not include these parameters in our study could be regarded as another limitation of this study. However, we were not aiming to find and explain as many factors as possible that contribute to the total variance of relative DTC of walking in a cohort of elderly. Our aim was to assess the specific contributions to this variance of three $\mathrm{EF}_{\mathrm{comp}}$. This study showed that especially divided attention contributes to the variance, which has potential relevance for future intervention studies.

\section{Conclusions}

Spatial and temporal dual task cost characteristics of gait are especially associated with divided attention in older adults. The results showed that the associated DTC differ by executive function and the nature of the task (preferred versus fast walking). Further research is needed to determine whether improvement in divided attention translates to better performance on selected complex walking tasks. The findings of this study of walking characteristics of well-functioning older adults prepare the groundwork for future interventional type studies to examine causality between DTC of walking and improvements in divided attention.

\footnotetext{
Acknowledgements

We gratefully acknowledge the support from Daniel Grob, MD and Claudine Geser, MD from the Waid Hospital Zurich who gave us the opportunity to perform the gait analysis in their facility. We also acknowledge the company PSYTEST Psychologische Testsysteme http://www.psytest.net for providing the neuropsychological assessment method for this study.
}

\section{Authors' contributions}

$E D B$, the guarantor, initiated the study, participated in its design, monitored progression and decided on the analytical strategy. He drafted the final manuscript and critically revised the manuscript for its content. AS conceived of the study, carried out the study, and drafted the first version of the manuscript. Both authors read and approved the final manuscript.

\section{Competing interests}

The authors declare that they have no competing interests.

Received: 15 June 2010 Accepted: 12 October 2010

Published: 12 October 2010

\section{References}

1. Berg WP, Alessio HM, Mills EM, Tong C: Circumstances and consequences of falls in independent community-dwelling older adults. Age Ageing 1997, 26:261-268.

2. Gill T, Taylor AW, Pengelly A: A population-based survey of factors relating to the prevalence of falls in older people. Gerontology 2005, 51:340-345.

3. Hausdorff JM, Rios DA, Edelberg HK: Gait variability and fall risk in community-living older adults: A 1-year prospective study. Arch Phys Med Rehabil 2001, 82:1050-1056.

4. Blake AJ, Morgan K, Bendall MJ, Dallosso H, Ebrahim SB, Arie TH, Fentem $\mathrm{PH}$, Bassey EJ: Falls by elderly people at home: Prevalence and associated factors. Age Ageing 1988, 17:365-372.

5. Rubenstein LZ: Falls in older people: Epidemiology, risk factors and strategies for prevention. Age Ageing 2006, 35(Suppl 2):ii37-ii41.

6. Tinetti ME, Doucette J, Claus E, Marottoli R: Risk factors for serious injury during falls by older persons in the community. J Am Geriatr Soc 1995, 43:1214-1221.

7. Bloem BR, Gussekloo J, Lagaay AM, Remarque EJ, Haan J, Westendorp RG: Idiopathic senile gait disorders are signs of subclinical disease. J Am Geriatr Soc 2000, 48:1098-1101.

8. Hakim AA, Petrovitch $\mathrm{H}$, Burchfiel CM, Ross GW, Rodriguez BL, White LR, Yano K, Curb JD, Abbott RD: Effects of walking on mortality among nonsmoking retired men. N Engl J Med 1998, 338:94-99.

9. Rapport LJ, Hanks RA, Millis SR, Deshpande SA: Executive functioning and predictors of falls in the rehabilitation setting. Arch Phys Med Rehabil 1998, 79:629-633.

10. Sheridan $\mathrm{PL}$, Hausdorff JM: The role of higher-level cognitive function in gait: Executive dysfunction contributes to fall risk in alzheimer's disease. Dement Geriatr Cogn Disord 2007, 24:125-137.

11. Sheridan PL, Solomont J, Kowall N, Hausdorff JM: Influence of executive function on locomotor function: Divided attention increases gait variability in alzheimer's disease. J Am Geriatr Soc 2003, 51:1633-1637.

12. Springer S, Giladi N, Peretz C, Yogev G, Simon ES, Hausdorff JM: Dualtasking effects on gait variability: The role of aging, falls, and executive function. Mov Disord 2006, 21:950-957.

13. Yogev-Seligmann G, Hausdorff JM, Giladi N: The role of executive function and attention in gait. Mov Disord 2008, 23:329-342, quiz 472.

14. Bryan J, LuszCz MA: Measurement of executive function: Considerations for detecting adult age differences. J Clin Exp Neuropsychol 2000, 22:40-55.

15. Shallice T: Specific impairments of planning. Philos Trans $R$ Soc Lond B Biol Sci 1982, 298:199-209.

16. Cicerone $\mathrm{K}$, Levin $\mathrm{H}$, Malec J, Stuss D, Whyte J: Cognitive rehabilitation interventions for executive function: Moving from bench to bedside in patients with traumatic brain injury. J Cogn Neurosci 2006, 18:1212-1222.

17. Rosano C, Aizenstein H, Cochran J, Saxton J, De Kosky S, Newman AB, Kuller LH, Lopez OL, Carter CS: Functional neuroimaging indicators of successful executive control in the oldest old. Neuroimage 2005, 28:881-889.

18. Hausdorff JM, Schweiger A, Herman T, Yogev-Seligmann G, Giladi N: Dualtask decrements in gait: Contributing factors among healthy older adults. J Gerontol A Biol Sci Med Sci 2008, 63:1335-1343.

19. Herman T, Mirelman A, Giladi N, Schweiger A, Hausdorff JM: Executive control deficits as a prodrome to falls in healthy older adults: A prospective study linking thinking, walking, and falling. J Gerontol A Biol Sci Med Sci 65:1086-1092.

20. Miyake A, Friedman NP, Emerson MJ, Witzki AH, Howerter A, Wager TD: The unity and diversity of executive functions and their contributions to complex "Frontal lobe" Tasks: A latent variable analysis. Cognit Psychol 2000, 41:49-100.

21. Royall DR, Lauterbach EC, Cummings JL, Reeve A, Rummans TA, Kaufer DI, LaFrance WC Jr, Coffey CE: Executive control function: A review of its promise and challenges for clinical research. A report from the committee on research of the american neuropsychiatric association. $J$ Neuropsychiatry Clin Neurosci 2002, 14:377-405. 
22. Chan RC, Chen EY, Cheung EF, Chen RY, Cheung HK: The components of executive functioning in a cohort of patients with chronic schizophrenia: A multiple single-case study design. Schizophr Res 2006, 81:173-189.

23. Crawford JR, Bryan J, LuszCz MA, Obonsawin MC, Stewart L: The executive decline hypothesis of cognitive aging: Do executive deficits qualify as differential deficits and do they mediate age-related memory decline? Neuropsychol Dev Cogn B Aging Neuropsychol Cogn 2000, 7:9-31.

24. Lin $H$, Chan RC, Zheng L, Yang T, Wang Y: Executive functioning in healthy elderly chinese people. Arch Clin Neuropsychol 2007, 22:501-511.

25. Plumet J, Gil R, Gaonac'h D: Neuropsychological assessment of executive functions in women: Effects of age and education. Neuropsychology 2005, 19:566-577.

26. Wecker NS, Kramer JH, Wisniewski A, Delis DC, Kaplan E: Age effects on executive ability. Neuropsychology 2000, 14:409-414.

27. Holtzer R, Verghese J, Xue X, Lipton RB: Cognitive processes related to gait velocity: Results from the einstein aging study. Neuropsychology 2006, 20:215-223.

28. Hausdorff JM, Yogev G, Springer S, Simon ES, Giladi N: Walking is more like catching than tapping: Gait in the elderly as a complex cognitive task. Exp Brain Res 2005, 164:541-548.

29. Folstein MF, Folstein SE, McHugh PR: "Mini-mental state". A practical method for grading the cognitive state of patients for the clinician. $J$ Psychiatr Res 1975, 12:189-198.

30. Bilney B, Morris M, Webster K: Concurrent related validity of the gaitrite walkway system for quantification of the spatial and temporal parameters of gait. Gait Posture 2003, 17:68-74.

31. McDonough AL, Batavia M, Chen FC, Kwon S, Ziai J: The validity and reliability of the gaitrite system's measurements: A preliminary evaluation. Arch Phys Med Rehabil 2001, 82:419-425.

32. Menz HB, Latt MD, Tiedemann A, Mun San Kwan M, Lord SR: Reliability of the gaitrite walkway system for the quantification of temporo-spatial parameters of gait in young and older people. Gait Posture 2004, 20:20-25.

33. van Uden CJ, Besser MP: Test-retest reliability of temporal and spatial gait characteristics measured with an instrumented walkway system (gaitrite). BMC Musculoskelet Disord 2004, 5:13.

34. Wittwer JE, Webster KE, Andrews PT, Menz HB: Test-retest reliability of spatial and temporal gait parameters of people with alzheimer's disease. Gait Posture 2008, 28:392-396.

35. Coppin AK, Shumway-Cook A, Saczynski JS, Patel KV, Ble A, Ferrucci L, Guralnik JM: Association of executive function and performance of dualtask physical tests among older adults: Analyses from the inchianti study. Age Ageing 2006, 35:619-624.

36. Lindenberger $U$, Marsiske $M$, Baltes PB: Memorizing while walking: Increase in dual-task costs from young adulthood to old age. Psychol Aging 2000, 15:417-436.

37. McDowd JM: The effects of age and extended practice on divided attention performance. J Gerontol 1986, 41:764-769.

38. Zimmermann P, Fimm B: Tap testbatterie zur aufmerksamkeitsprüfung, version 1.7. Herzogenrath: Psytest 2002.

39. Beck L, Heusinger A, Boecker M, Niemann H, Gauggel S: Convergent and predictive validity of two computerized attention tests in braindamaged patients. Zeitschrift für Neuropsychologie 2008, 19:213-222.

40. Bühner $M$, Ziegler M, Bohnes B, Lauterbach K: Übungseffekte in den tap untertests go/nogo und geteilte aufmerksamkeit sowie dem aufmerksamkeits-belastungstest (d2). Z. Neuropsychol 2006, 17:191-199.

41. Becker M, Sturm W, Willmes K, Zimmermann P: Normierungsstudie zur aufmerksamkeitstestbatterie (tap) von zimmermann und fimm [a normative study on the attention test battery (tap) by zimmermann and fimm]. Zeitschrift für Neuropsychologie 1996, 7:3-15.

42. Wallat M, Hartje W, Willmes K: Erprobung eines computergestützten verfahrens zur prüfung der geteilten aufmerksamkeit mit hirngeschädigten patienten [evaluation of a computerized test of divided attention with brain-damaged patients]. Zeitschrift für Neuropsychologie 1995, 6:128-136.

43. Yardley L, Beyer N, Hauer K, Kempen G, Piot-Ziegler C, Todd C: Development and initial validation of the falls efficacy scaleinternational (fes-i). Age Ageing 2005, 34:614-619.

44. Sarter M, Turchi J: Age- and dementia-associated impairments in divided attention: Psychological constructs, animal models, and underlying neuronal mechanisms. Dement Geriatr Cogn Disord 2002, 13:46-58.
45. Carlson MC, Fried LP, Xue QL, Bandeen-Roche K, Zeger SL, Brandt J: Association between executive attention and physical functional performance in community-dwelling older women. J Gerontol B Psychol Sci Soc Sci 1999, 54:S262-270.

46. Vazzana R, Bandinelli S, Lauretani F, Volpato S, Di lorio A, Abate M, Corsi AM, Milaneschi Y, Guralnik JM, Ferrucci L: Trail making test predicts physical impairment and mortality in older persons. J Am Geriatr SoC 58:719-723.

47. Litvan I, Mohr E, Williams J, Gomez C, Chase TN: Differential memory and executive functions in demented patients with parkinson's and alzheimer's disease. J Neurol Neurosurg Psychiatry 1991, 54:25-29.

48. Rosano C, Aizenstein H, Brach J, Longenberger A, Studenski S, Newman AB: Special article: Gait measures indicate underlying focal gray matter atrophy in the brain of older adults. J Gerontol A Biol Sci Med Sci 2008, 63:1380-1388.

49. Echterhoff J, Golzarandi AG, Morsch D, Lehmkuhl G, Sinzig J: Ein vergleich computergestützter testverfahren zur neuropsychologischen diagnostik bei aufmerksamkeitsdefizit-/hyper-aktivitätsstörung. Zeitschrift für Neuropsychologie 2009, 20:313-325.

50. Pajala S, Era P, Koskenvuo M, Kaprio J, Alen M, Tolvanen A, Tiainen K, Rantanen T: Contribution of genetic and environmental factors to individual differences in maximal walking speed with and without second task in older women. J Gerontol A Biol Sci Med Sci 2005, 60:1299-1303.

51. Li KZ, Lindenberger U: Relations between aging sensory/sensorimotor and cognitive functions. Neurosci Biobehav Rev 2002, 26:777-783.

52. Bock O: Dual-task costs while walking increase in old age for some, but not for other tasks: An experimental study of healthy young and elderly persons. J Neuroeng Rehabil 2008, 5:27.

doi:10.1186/1744-9081-6-59

Cite this article as: de Bruin and Schmidt: Walking behaviour of healthy elderly: attention should be paid. Behavioral and Brain Functions 2010 6:59.

\section{Submit your next manuscript to BioMed Central and take full advantage of:}

- Convenient online submission

- Thorough peer review

- No space constraints or color figure charges

- Immediate publication on acceptance

- Inclusion in PubMed, CAS, Scopus and Google Scholar

- Research which is freely available for redistribution

Submit your manuscript at www.biomedcentral.com/submit
C Biomed Central 